\title{
Geochronology of flood basalts provinces: where are we, and what's next?
}

\section{BLAIR SCHOENE}

Princeton University

Presenting Author: bschoene@princeton.edu

Large igneous provinces (LIPs) and their relationship to mass extinctions have been at the center of improvements in the precision and accuracy of geochronology. Correlations between intrusive and extrusive magmatism and biotic and paleoclimate records have become more acute, which has in turn led to new questions about how LIPs may drive ecological change. Recent compilations of geochronologic data from well-dated LIPs show that terrestrial LIPs erupt in $<1 \mathrm{Ma}$, and seem to begin several hundred ka before mass extinction events. The need for yet higher precision dates with geologic context that permits determining rates of magmatic events have led to creative sampling, sample processing, and analytical innovations in geochronology. It also calls for continued diligence of geochronologists in connecting high precision dates to processes that most likely effect the climate and biosphere, such as eruption and emplacement rates and volatile emissions.

In this contribution, I will use recent work from my group and collaborators from the Deccan Traps and Columbia River Basalt Group to highlight our attempts to develop high resolution eruption records of these LIPs using U-Pb ID-TIMS geochronology of zircon. By dating volcanic zircon from ashbearing horizons between basalt flows, and combining these data with estimates for volumes of various basalt formations, we calculate eruption rates with high precision, and show non-linear eruption rates in both cases, but with hiatuses of up to $100 \mathrm{ka}$ in the Deccan. Good agreement between $\mathrm{U}-\mathrm{Pb}$ and recent Ar-Ar geochronology highlights the importance of applying both methods to capitalize on the strength of each and continue intercalibration efforts. Connecting the new eruption rates to climate records is not straightforward, pointing to uncertainties in lava volume estimates, volatile contents, the importance of intrusive components of the LIPs that have not been dated, or our imperfect understanding of the carbon cycle, and future work must continue multidisciplinary approach to understanding LIPs, mass extinctions, and climate. 